Rev. Bras. Saúde Prod. Anim., Salvador, v.13, n.1, p.160-172 jan/mar, 2012 http://www.rbspa.ufba.br ISSN 15199940

\title{
Raspa integral da raiz de mandioca para frangas de um a 42 dias de idade
}

\author{
Integral scrapings from cassava root for pullets from 1 to 42 days old
}

\author{
FERREIRA, Antônio Hosmylton Carvalho ${ }^{1 *}$; LOPES, João Batista ${ }^{1}$, ABREU, Márvio \\ Lobão Teixeira ${ }^{1}$; FIGUEIRÊDO, Agostinho Valente ${ }^{1}$; RIBEIRO, Mabel Nery ${ }^{1}$; SILVA, \\ Francisco Eduardo Soares ${ }^{1}$; MERVAL, Ramon Rego ${ }^{1}$
}

${ }^{1}$ Universidade Federal do Piauí, Centro de Ciências Agrárias, Departamento de Zootecnia, Teresina,
Piauí, Brasil.
${ }^{*}$ Endereço para correspondência: hosmylton@hotmail.com

\section{RESUMO}

A pesquisa foi realizada para avaliar o efeito dos níveis de inclusão da raspa integral da raiz da mandioca sobre o desempenho produtivo de frangas da linhagem Ross no período de um a 42 dias de idade, bem como as características da carcaça aos 42 dias de idade. O delineamento experimental foi de blocos ao acaso, com cinco tratamentos e quatro repetições. A unidade experimental foi representada por 20 aves, alojadas em cada box. Os tratamentos consistiram de rações que continham diferentes níveis de inclusão da raspa da raiz integral de mandioca $(0 ; 5 ; 10 ; 15$ e $20 \%)$, formuladas para atender as exigências nutricionais de acordo com cada fase da criação, e foram utilizados quatro programas de alimentação. A inclusão da raspa integral não afetou o ganho de peso e a viabilidade da criação de frangas de corte no período de um a 42 dias, para ganho de peso e viabilidade da criação. No entanto, o consumo de ração e a conversão alimentar foram influenciados pelos níveis de inclusão da raspa integral de mandioca. Pode-se utilizar em dietas balanceadas de frangas de corte, no período de 1 a 42 dias, até o nível de $6,77 \%$, sem comprometer as características da carcaça e o rendimento dos principais cortes e dos órgãos comestíveis.

Palavras chave: carcaça, desempenho, ganho de peso, nutrição

\section{SUMMARY}

This research was developed to evaluate the effect of inclusion the levels of integral scraping of cassava roots on performance and carcass characteristic of pullets of Ross strain, in the period from 1 to 42 days. The experimental design was a randomized block with five treatments and four replications, being the experimental unit represented by twenty birds, housed in each box. The treatments consisted of diets containing different levels of inclusion of integral scraping of cassava root $(0 ; 5 ; 10 ; 15$ and $20 \%$ ), formulated to attend the nutritional requirements according to each phase of the birds, using four feeding programs. The inclusion of scrapings of cassava root in diets did not affect the weight gain and feasibility of housing of pullets in the period from 1 to 42 days. However, feed intake and feed conversion were affected with inclusion levels scraping cassava root. The scrapings of cassava root can be used in diets of pullets, in the period from 1 to 42 days in levels up to $6.77 \%$, without compromising carcass characteristics and main cuts and edible organs.

Keywords: carcass, nutrition, performance, weight gain 


\section{INTRODUÇÃO}

As dietas tradicionais para aves são formuladas, principalmente, com milho grão e farelo de soja, que apresentam grande oscilação de preço, tanto dentro do ano agrícola, nos período da entressafra, como entre anos, devido à ocorrência de estiagens e às oscilações de preços no mercado externo, o que reduz a oferta.

A demanda por esses produtos tem crescido no cenário mundial, principalmente, com utilização desses ingredientes como biocombustíveis, bem como, pelo aumento do consumo de alimentos em países em desenvolvimento como China e Índia, detentores de grande contingentes populacionais. Tais constatações exigem do meio científico buscar alternativas viáveis, avaliar novos produtos, coprodutos ou subprodutos para serem utilizados na alimentação humana e animal.

Assim, a mandioca (Manihot esculenta, Crantz) se destaca na região Nordeste do Brasil pelos altos índices de produtividade, em função de sua adaptação às diferentes condições de adversidades do meio, do fácil manuseio de seus produtos e principalmente, pelo valor nutricional que apresenta. De acordo com Almeida \& Ferreira Filho (2005), os maiores produtores do país são os estados do Pará, Paraná e Bahia.

A mandioca é considerada a principal fonte de carboidratos para milhões de pessoas. Segundo Nascimento et al. (2005), essa planta, tipicamente brasileira, é cultivada em mais de dois milhões de hectares, com produtividade média de 13,2 t./ha. As raízes são excelentes fontes de energia, suas folhas ricas em proteína, e podem ser utilizadas tanto na alimentação humana como animal. Conforme Ferreira et al. (2007), as frações dos carboidratos e os valores de energia de subprodutos da mandioca constituem características favoráveis para a alimentação de não ruminantes. $\mathrm{Na}$ alimentação animal, a mandioca pode ser usada sob as formas de raízes frescas ou raspas "pellets" e de farelos obtidos das partes aéreas (ramas e folhas) e raízes (FASUYI \& ALETOR, 2005).

A pesquisa foi realizada para avaliar o efeito de diferentes níveis de inclusão da raspa integral da raiz da mandioca $(0 ; 5 ; 10 ; 15$ e $20 \%)$, em dietas de frangas de corte, no período de um a 42 dias sobre o desempenho produtivo (ganho de peso, consumo de ração e conversão alimentar), viabilidade da criação e índice de eficiência produtiva, bem como o rendimento de carcaça, dos principais cortes (peito, dorso, coxas, sobrecoxas, asas e entreasas) e dos órgãos comestíveis (fígado, coração e moela), em frangos de corte aos 42 dias de idade.

\section{MATERIAL E MÉTODOS}

A pesquisa foi realizada no Galpão Experimental do Setor de Avicultura do Departamento de Zootecnia do Centro de Ciências Agrárias da Universidade Federal do Piauí (DZO-CCA-UFPI), em Teresina, Piauí. Utilizaram-se 400 pintaínhas fêmeas da linhagem Ross, no período de um a 42 dias de idade, selecionadas individualmente por peso e a identificação do sexo feita por meio da asa.

Os animais foram distribuídos em delineamento de blocos ao acaso, conforme o peso das aves, com cinco tratamentos e quatro repetições, e cada unidade experimental representada por 20 aves. Os boxes ocupavam, individualmente, uma área de $3,00 \mathrm{~m}^{2}$, distribuídos num galpão de alvenaria 
coberto com telhas de barro, piso cimentado e com cortinas para controle das correntes de ar e da temperatura. As divisórias entre os boxes eram de tela de arame liso.

O manejo dos animais durante todo o período experimental foi semelhante ao recomendado pelo manual de criação da linhagem Ross, e a cama utilizada nos boxes foi de casca de arroz, com espessura de aproximadamente de $5 \mathrm{~cm}$.

As dietas experimentais consistiram de rações formuladas à base de milho, farelo de soja, fosfato bicálcico, calcário, sal comum, suplemento vitamínico e mineral (Tabelas 1, 2, 3 e 4), que continham níveis de inclusão da raspa integral de raiz de mandioca $(0 ; 5 ; 10 ; 15$ e 20\%), formuladas para atender as exigências nutricionais, segundo Rostagno et al. (2005). Foram utilizados quatro programas de alimentação.

O programa de luz foi contínuo, durante as 24 horas do dia, de modo que das $06 \mathrm{~h} 30 \mathrm{~min}$ às $17 \mathrm{~h} 30 \mathrm{~min}$, utilizou-se iluminação natural, e no restante luz artificial obtida por meio de lâmpadas fluorescentes de 75 watts. As aves receberam água limpa e ração ad libitum, sistema de aquecimento nos 10 primeiros dias realizado por meio de lâmpadas incandescentes. O programa de vacinação contra as doenças de bronquite infecciosa, newcastle e gumboro foi realizado ainda no incubatório.

$\mathrm{O}$ monitoramento da temperatura $\mathrm{e}$ da umidade do galpão foi feito por meio de termohigrômetro, de máxima e mínima, colocado à altura intermediária em relação aos boxes. As leituras dos termômetros foram realizadas, diariamente, duas vezes ao dia $(07 \mathrm{~h} 30 \mathrm{~min}$ e $15 \mathrm{~h} 30 \mathrm{~min})$. Nos períodos do dia em que a temperatura ultrapassou a zona de termoneutralidade foram acionados ventiladores elétricos para amenizar o estresse calórico.
Para determinação do consumo de ração e do ganho de peso, tanto as rações como as aves foram pesadas no início e no final de cada fase experimental. O consumo de ração foi calculado por diferença entre a quantidade de ração fornecida e os desperdícios e as sobras das rações experimentais. A partir dos dados de consumo de ração e ganho de peso, foi calculada a conversão alimentar dos animais.

Aos 42 dias de idade foram escolhidas duas aves por box, que apresentavam peso médio do grupo, o que totalizou oito aves por tratamento. Os frangos, submetidos a um jejum de seis horas foram pesados e sacrificados segundo os procedimentos normais de abate: deslocamento cervical, sangria, depenagem e evisceração.

Após o sangramento e a depenagem, as aves foram evisceradas e as carcaças (exceto cabeça, pescoço e pés) pesadas. Posteriormente foi retirada toda a gordura abdominal. O rendimento de carcaça foi determinado pela relação entre o peso da carcaça eviscerada, sem pés, sem cabeça e sem gordura, e o peso vivo das aves na plataforma de abate. Também, foi determinado o rendimento percentual da carcaça e dos cortes.

Os cortes (peito, dorso, asas, entreasas, coxas e sobrecoxas), foram pesados em balança digital e seus rendimentos calculados em relação ao peso da carcaça eviscerada, e assim, avaliados o peso absoluto $(\mathrm{g})$ e o rendimento $(\%)$ das carcaças (sem pés e sem cabeça e pescoço), dos cortes citados e dos órgãos comestíveis (coração, fígado e moela).

$\mathrm{O}$ índice de viabilidade da criação (VC) foi calculado pela subtração de 100 pelo valor da mortalidade (\%) encontrado, enquanto $\mathrm{o}$ índice de eficiência produtiva (IEP), pela fórmula 
Rev. Bras. Saúde Prod. Anim., Salvador, v.13, n.1, p.160-172 jan/mar, 2012 http://www.rbspa.ufba.br ISSN 15199940

$\mathrm{IEP}=[(\mathrm{GP} \times \mathrm{VC}) /($ dias até o final do $\left.\begin{array}{llll}\text { experimento } & \mathrm{x} & \mathrm{CA})\end{array}\right] \quad \mathrm{x} \quad 100$ (STRINGHINI et al., 2006).

Os resultados foram submetidos à análise da variância e teste de regressão, de acordo com os procedimentos do Statistical Analysis System (SAS INSTITUTE, 1986).

Tabela 1. Composição das dietas experimentais em função dos níveis de inclusão da raspa integral da raiz de mandioca, no período de um a sete dias de idade

\begin{tabular}{|c|c|c|c|c|c|}
\hline \multirow{2}{*}{ Ingredientes } & \multicolumn{5}{|c|}{ Níveis de inclusão da raspa integral da mandioca (\%) } \\
\hline & 0 & 5 & 10 & 15 & 20 \\
\hline Milho & 54,815 & 48,125 & 41,696 & 35,238 & 28,900 \\
\hline Farelo de soja $45 \%$ & 38,645 & 39,627 & 40,507 & 41,400 & 42,275 \\
\hline Óleo Vegetal & 2,566 & 3,215 & 3,785 & 4,385 & 4,873 \\
\hline Raspa mandioca & 0,000 & 5,000 & 10,000 & 15,000 & 20,000 \\
\hline Fosfato bicálcico & 1,928 & 1,935 & 1,950 & 1,970 & 1,970 \\
\hline Calcário calcítico & 0,930 & 0,905 & 0,865 & 0,829 & 0,809 \\
\hline $\mathrm{NaCl}$ & 0,325 & 0,325 & 0,325 & 0,325 & 0,325 \\
\hline L-Lisina & 0,129 & 0,119 & 0,112 & 0,087 & 0,072 \\
\hline DL-metionina & 0,182 & 0,269 & 0,280 & 0,286 & 0,296 \\
\hline Premix min./ viatm. ${ }^{1}$ & 0,200 & 0,200 & 0,200 & 0,200 & 0,200 \\
\hline Material inerte & 0,040 & 0,040 & 0,040 & 0,040 & 0,040 \\
\hline Cloreto de colina & 0,125 & 0,125 & 0,125 & 0,125 & 0,125 \\
\hline Virginiamicina & 0,055 & 0,055 & 0,055 & 0,055 & 0,055 \\
\hline Coxistac & 0,050 & 0,050 & 0,050 & 0,050 & 0,050 \\
\hline BHT & 0,010 & 0,010 & 0,010 & 0,010 & 0,010 \\
\hline Enzimas $^{2}$ & 0,020 & 0,020 & 0,020 & 0,020 & 0,020 \\
\hline Total & 100,000 & 100,000 & 100,000 & 100,000 & 100,000 \\
\hline \multicolumn{6}{|c|}{ Composição calculada $^{1}$} \\
\hline PB (\%) & 22,04 & 22,04 & 22,04 & 22,04 & 22,04 \\
\hline EM (kcal kg & 2950 & 2950 & 2950 & 2950 & 2950 \\
\hline FB $(\%)$ & 3,04 & 3,25 & 3,45 & 3,66 & 3,87 \\
\hline $\mathrm{Ca}(\%)$ & 0,94 & 0,94 & 0,94 & 0,94 & 0,94 \\
\hline Pdisponível (\%) & 0,47 & 0,47 & 0,47 & 0,47 & 0,47 \\
\hline Lisina $(\%)$ & 1,330 & 1,330 & 1,330 & 1,330 & 1,330 \\
\hline Metion+cistina $(\%)$ & 0,944 & 0,944 & 0,944 & 0,944 & 0,944 \\
\hline Triptofano $(\%)$ & 0,213 & 0,213 & 0,213 & 0,213 & 0,213 \\
\hline
\end{tabular}

${ }^{1}$ Composição premix: Ácido Fólico - 100mg, Antioxidante - 125mg, Cobre - 15.000mg, Coccidiostático 25.000mg, Colina - 50.000mg, Ferro - 10.000mg, Iodo - 250mg, Manganês - 24.000mg, Metionina 307.000mg, Niacina - 20.000mg, Pantotenato de cálcio - 2.000mg, Selênio - 50mg, Veículo QSP - 1.000g, Vitamina A - 300.000UI/Kg, Vitamina B1 - 400g, Vitamina B12 - 4.000mcg, Vitamina B2 - 1.320mg, Vitamina D3 - 100.000UI/Kg, Vitamina E - 4.000UI/Kg, Vitamina K - 98mg, Zinco - 20.000mg, promotor de crescimento $-10.000 \mathrm{mg}$

${ }^{2}$ Amilase, protease e celulase, juntamente com fitase, de acordo com a recomendação do fabricante.

${ }^{3}$ Baseada em Rostagno et al. (2005). 
Rev. Bras. Saúde Prod. Anim., Salvador, v.13, n.1, p.160-172 jan/mar, 2012 http://www.rbspa.ufba.br ISSN 15199940

Tabela 2. Composição das dietas experimentais em função dos níveis de inclusão da raspa integral da raiz da mandioca, no período de oito a 21 dias de idade

\begin{tabular}{|c|c|c|c|c|c|}
\hline \multirow{2}{*}{ Ingredientes } & \multicolumn{5}{|c|}{ Níveis de inclusão da raspa integral da mandioca (\%) } \\
\hline & 0 & 5 & 10 & 15 & 20 \\
\hline Milho & 58,656 & 51,973 & 45,634 & 39,204 & 32,616 \\
\hline Farelo de soja & 35,168 & 36,147 & 36,990 & 37,900 & 38,859 \\
\hline Óleo Vegetal & 2,510 & 3,220 & 3,720 & 4,265 & 4,900 \\
\hline Raspa Mandioca & 0,000 & 5,000 & 10,000 & 15,000 & 20,000 \\
\hline Fosfato bicálcico & 1,795 & 1,825 & 1,825 & 1,825 & 1,840 \\
\hline Calcário calcítico & 0,890 & 0,825 & 0,825 & 0,795 & 0,765 \\
\hline $\mathrm{NaCl}$ & 0,325 & 0,325 & 0,325 & 0,325 & 0,325 \\
\hline L-Lisina & 0,031 & 0,015 & 0,005 & 0,000 & 0,000 \\
\hline DL-metionina & 0,125 & 0,170 & 0,176 & 0,186 & 0,195 \\
\hline Premix min./ vitam. ${ }^{1}$ & 0,200 & 0,200 & 0,200 & 0,200 & 0,200 \\
\hline Material inerte & 0,040 & 0,040 & 0,040 & 0,040 & 0,040 \\
\hline Cloreto de colina & 0,125 & 0,125 & 0,125 & 0,125 & 0,125 \\
\hline Virginiamicina & 0,055 & 0,055 & 0,055 & 0,055 & 0,055 \\
\hline Coxistac & 0,050 & 0,050 & 0,050 & 0,050 & 0,050 \\
\hline BHT & 0,010 & 0,010 & 0,010 & 0,010 & 0,010 \\
\hline Enzimas $^{2}$ & 0,020 & 0,020 & 0,020 & 0,020 & 0,020 \\
\hline Total & 100,000 & 100,000 & 100,000 & 100,000 & 100,000 \\
\hline \multicolumn{6}{|c|}{ Composição calculada $^{3}$} \\
\hline PB (\%) & 20,790 & 20,790 & 20,790 & 20,790 & 20,790 \\
\hline EM (kcal kg) & 3000 & 3000 & 3000 & 3000 & 3000 \\
\hline FB $(\%)$ & 2,919 & 3,126 & 3,333 & 3,542 & 3,751 \\
\hline $\mathrm{Ca}(\%)$ & 0,884 & 0,884 & 0,884 & 0,884 & 0,884 \\
\hline Pdisponível (\%) & 0,442 & 0,442 & 0,442 & 0,442 & 0,442 \\
\hline Lisina (\%) & 1,146 & 1,146 & 1,146 & 1,146 & 1,146 \\
\hline Metion+cistina (\%) & 0,814 & 0,814 & 0,814 & 0,814 & 0,814 \\
\hline Triptofano (\%) & 0,183 & 0,183 & 0,183 & 0,183 & 0,183 \\
\hline
\end{tabular}

${ }^{1}$ Composição premix: Ácido Fólico - 100mg, Antioxidante - 125mg, Cobre - 15.000mg, Coccidiostático $-25.000 \mathrm{mg}$, Colina $-50.000 \mathrm{mg}$, Ferro $-10.000 \mathrm{mg}$, Iodo $-250 \mathrm{mg}$, Manganês $-24.000 \mathrm{mg}$, Metionina $307.000 \mathrm{mg}$, Niacina $-20.000 \mathrm{mg}$, Pantotenato de cálcio $-2.000 \mathrm{mg}$, Selênio $-50 \mathrm{mg}$, Veículo QSP $1.000 \mathrm{~g}$, Vitamina A - 300.000UI/Kg, Vitamina B1 - 400g, Vitamina B12 - 4.000mcg, Vitamina B2 $1.320 \mathrm{mg}$, Vitamina D3 - $100.000 \mathrm{UI} / \mathrm{Kg}$, Vitamina E - $4.000 \mathrm{UI} / \mathrm{Kg}$, Vitamina K - 98mg, Zinco $20.000 \mathrm{mg}$, promotor de crescimento $-10.000 \mathrm{mg}$.

${ }^{2}$ Amilase, protease e celulase, juntamente com fitase, de acordo com a recomendação do fabricante.

${ }^{3}$ Baseada em Rostagno et al. (2005). 
Rev. Bras. Saúde Prod. Anim., Salvador, v.13, n.1, p.160-172 jan/mar, 2012 http://www.rbspa.ufba.br ISSN 15199940

Tabela 3. Composição das dietas experimentais, em função dos níveis de inclusão da raspa integral da raiz de mandioca, no período de 22 a 33 dias de idade

\begin{tabular}{|c|c|c|c|c|c|}
\hline \multirow{2}{*}{ Ingredientes } & \multicolumn{5}{|c|}{ Níveis de inclusão da raspa integral da mandioca (\%) } \\
\hline & 0 & 5 & 10 & 15 & 20 \\
\hline Milho & 61,368 & 54,603 & 48,100 & 41,640 & 35,340 \\
\hline Farelo de soja & 31,626 & 32,607 & 33,525 & 34,430 & 35,300 \\
\hline Óleo Vegetal & 3,510 & 4,220 & 4,820 & 5,430 & 5,860 \\
\hline Raspa Mandioca & 0,000 & 5,000 & 10,000 & 15,000 & 20,000 \\
\hline Fosfato bicálcico & 1,646 & 1,825 & 1,840 & 1,840 & 1,840 \\
\hline Calcário calcítico & 0,850 & 0,715 & 0,690 & 0,650 & 0,650 \\
\hline $\mathrm{NaCl}$ & 0,325 & 0,325 & 0,325 & 0,325 & 0,325 \\
\hline L-Lisina & 0,050 & 0,040 & 0,025 & 0,005 & 0,005 \\
\hline DL-metionina & 0,125 & 0,165 & 0,175 & 0,180 & 0,180 \\
\hline Premix min./ vitam. ${ }^{1}$ & 0,200 & 0,200 & 0,200 & 0,200 & 0,200 \\
\hline Material inerte & 0,040 & 0,040 & 0,040 & 0,040 & 0,040 \\
\hline Cloreto de colina & 0,125 & 0,125 & 0,125 & 0,125 & 0,125 \\
\hline Virginiamicina & 0,055 & 0,055 & 0,055 & 0,055 & 0,055 \\
\hline Coxistac & 0,050 & 0,050 & 0,050 & 0,050 & 0,050 \\
\hline BHT & 0,010 & 0,010 & 0,010 & 0,010 & 0,010 \\
\hline Enzimas $^{2}$ & 0,020 & 0,020 & 0,020 & 0,020 & 0,020 \\
\hline Total & 100,000 & 100,000 & 100,000 & 100,000 & 100,000 \\
\hline \multicolumn{6}{|c|}{ Composição calculada $^{1}$} \\
\hline PB (\%) & 19,410 & 19,410 & 19,410 & 19,410 & 19,410 \\
\hline EM (kcal kg & 3100 & 3100 & 3100 & 3100 & 3100 \\
\hline FB $(\%)$ & 2,774 & 2,980 & 3,188 & 3,396 & 3,605 \\
\hline $\mathrm{Ca}(\%)$ & 0,824 & 0,824 & 0,824 & 0,824 & 0,824 \\
\hline Pdisponível (\%) & 0,441 & 0,441 & 0,441 & 0,441 & 0,441 \\
\hline Lisina $(\%)$ & 1,073 & 1,073 & 1,073 & 1,073 & 1,073 \\
\hline Metion+cistina (\%) & 0,773 & 0,773 & 0,773 & 0,773 & 0,773 \\
\hline Triptofano (\%) & 0,182 & 0,182 & 0,182 & 0,182 & 0,182 \\
\hline
\end{tabular}

${ }^{1}$ Composição premix: Ácido Fólico - 100mg, Antioxidante - 125mg, Cobre - 15.000mg, Coccidiostático $-12.000 \mathrm{mg}$, Ferro $-10.000 \mathrm{mg}$, Iodo $-250 \mathrm{mg}$, Manganês $-24.000 \mathrm{mg}$, Metionina $-135.000 \mathrm{mg}$, Niacina - 20.000g, Pantotenato de cálcio - 2.000mg, Selênio - 50g, Veículo QSP - $1.000 \mathrm{~g}$, Vitamina A $300.000 \mathrm{UI} / \mathrm{kg}$, Vitamina B1 - 400mg, Vitamina B12 - 4.000mcg, Vitamina B2 - 720mg, Vitamina D3 $100.000 \mathrm{UI} / \mathrm{kg}$, Vitamina E - 4000UI/kg, Vitamina K - 98mg, Zinco - 20.000mg, Promotor de Crescimento - $10.000 \mathrm{mg}$

${ }^{2}$ Amilase, protease e celulase, juntamente com fitase, de acordo com a recomendação do fabricante.

${ }^{3}$ Baseada em Rostagno et al. (2005). 
Rev. Bras. Saúde Prod. Anim., Salvador, v.13, n.1, p.160-172 jan/mar, 2012 http://www.rbspa.ufba.br ISSN 15199940

Tabela 4. Composição das dietas experimentais em função dos níveis de inclusão da raspa integral da raiz de mandioca, no período de 34 a 42 dias de idade

\begin{tabular}{|c|c|c|c|c|c|}
\hline \multirow{2}{*}{ Ingredientes } & \multicolumn{5}{|c|}{ Níveis de inclusão da raspa integral da mandioca } \\
\hline & $0 \%$ & $5 \%$ & $10 \%$ & $15 \%$ & $20 \%$ \\
\hline Milho & 65,205 & 58,508 & 52,108 & 45,703 & 39,193 \\
\hline Farelo de soja & 27,875 & 28,827 & 29,727 & 30,627 & 31,537 \\
\hline Óleo Vegetal & 3,550 & 4,220 & 4,750 & 5,290 & 5,910 \\
\hline Raspa Mandioca & 0,000 & 5,000 & 10,000 & 15,000 & 20,000 \\
\hline Fosfato bicálcico & 1,500 & 1,525 & 1,525 & 1,540 & 1,550 \\
\hline Calcário calcítico & 0,805 & 0,770 & 0,740 & 0,700 & 0,670 \\
\hline $\mathrm{NaCl}$ & 0,220 & 0,325 & 0,325 & 0,325 & 0,325 \\
\hline L-Lisina & 0,090 & 0,070 & 0,060 & 0,045 & 0,035 \\
\hline DL-metionina & 0,120 & 0,155 & 0,165 & 0,170 & 0,180 \\
\hline Premix min./ vitam. ${ }^{1}$ & 0,200 & 0,200 & 0,200 & 0,200 & 0,200 \\
\hline Material inerte & 0,040 & 0,005 & 0,005 & 0,005 & 0,005 \\
\hline Cloreto de colina & 0,125 & 0,125 & 0,125 & 0,125 & 0,125 \\
\hline Virginiamicina & 0,055 & 0,055 & 0,055 & 0,055 & 0,055 \\
\hline Coxistac & 0,050 & 0,050 & 0,050 & 0,050 & 0,050 \\
\hline BHT & 0,010 & 0,010 & 0,010 & 0,010 & 0,010 \\
\hline Enzimas $^{2}$ & 0,020 & 0,020 & 0,020 & 0,020 & 0,020 \\
\hline Total & 100,000 & 100,000 & 100,000 & 100,000 & 100,000 \\
\hline \multicolumn{6}{|c|}{ Composição calculada $^{3}$} \\
\hline PB (\%) & 18,030 & 18,030 & 18,030 & 18,030 & 18,030 \\
\hline EM (kcal kg) & 3150 & 3150 & 3150 & 3150 & 3150 \\
\hline FB $(\%)$ & 2,638 & 2,844 & 3,053 & 3,262 & 3,470 \\
\hline $\mathrm{Ca}(\%)$ & 0,763 & 0,763 & 0,763 & 0,763 & 0,763 \\
\hline P disponível (\%) & 0,380 & 0,380 & 0,380 & 0,380 & 0,380 \\
\hline Lisina $(\%)$ & 1,017 & 1,017 & 1,017 & 1,017 & 1,017 \\
\hline Metion+cistina(\%) & 0,732 & 0,732 & 0,732 & 0,732 & 0,732 \\
\hline Triptonano (\%) & 0,173 & 0,173 & 0,173 & 0,173 & 0,173 \\
\hline
\end{tabular}

${ }^{1}$ Composição premix: Ácido Fólico - 100mg, Antioxidante - 125mg, Cobre - 15.000mg, Coccidiostático $-12.000 \mathrm{mg}$, Ferro $-10.000 \mathrm{mg}$, Iodo $-250 \mathrm{mg}$, Manganês $-24.000 \mathrm{mg}$, Metionina $-135.000 \mathrm{mg}$, Niacina $-20.000 \mathrm{~g}$, Pantotenato de cálcio $-2.000 \mathrm{mg}$, Selênio $-50 \mathrm{~g}$, Veículo QSP $-1.000 \mathrm{~g}$, Vitamina A $300.000 \mathrm{UI} / \mathrm{kg}$, Vitamina B1 - 400mg, Vitamina B12 - 4.000mcg, Vitamina B2 - 720mg, Vitamina D3 $100.000 \mathrm{UI} / \mathrm{kg}$, Vitamina E - 4000UI/kg, Vitamina K $-98 \mathrm{mg}$, Zinco $-20.000 \mathrm{mg}$, Promotor de Crescimento $-10.000 \mathrm{mg}$.

${ }^{2}$ Amilase, protease e celulase, juntamente com fitase, de acordo com a recomendação do fabricante.

${ }^{3}$ Baseada em Rostagno et al. (2005). 


\section{RESULTADOS E DISCUSSÃO}

Os valores médios de temperatura obtidos nos turnos da manhã e da tarde foram, respectivamente, de $28,6 \pm 1,8^{\circ} \mathrm{C}$ e $33,7 \pm 2,6^{\circ} \mathrm{C}$ e a umidade relativa do ar, $55,7 \pm 17,2 \%$. Esses resultados revelam que a pesquisa foi desenvolvida em ambiente de altas temperaturas, com as aves submetidas a estresse térmico segundo as recomendações de $\mathrm{COOB}$ (2009) e Ferreira (2005).
Constatou-se que não houve efeito significativo $(\mathrm{P}>0,05)$ dos níveis de inclusão da raspa integral da raiz da mandioca na alimentação de frangas de corte no período de um a 42 dias para ganho de peso e viabilidade da criação (Tabela 5). Carrijo et al. (2010), ao trabalharem com níveis de inclusão de farelo da raiz integral de mandioca em dietas para fêmeas de frangos caipiras, não observaram diferenças nas variáveis de desempenho analisadas durante as fases de criação das aves.

Tabela 5. Desempenho de frangas de corte alimentadas com rações contendo diferentes níveis de inclusão de raspa integral da raiz de mandioca, no período de um a 42 dias de idade

\begin{tabular}{|c|c|c|c|c|c|c|}
\hline \multirow{2}{*}{ Variáveis } & \multicolumn{5}{|c|}{ Níveis de inclusão da raspa integral da mandioca (\%) } & \multirow{2}{*}{$\mathrm{CV}(\%)$} \\
\hline & 0 & 5 & 10 & 15 & 20 & \\
\hline Consumo de ração $(\mathrm{kg})^{1}$ & 3,824 & 3,408 & 3,746 & 3,719 & 4,177 & 7,29 \\
\hline Ganho de peso $(\mathrm{kg})$ & 1,929 & 1,791 & 1,802 & 1,900 & 1,994 & 5,66 \\
\hline Conversão alimentar $(\mathrm{kg} / \mathrm{kg})^{1}$ & 1,982 & 1,791 & 1,802 & 1,900 & 2,094 & 5,22 \\
\hline Viabilidade (\%) & 96,250 & 92,500 & 92,500 & 92,500 & 97,500 & 7,47 \\
\hline Índice Eficiência Produtiva ${ }^{1}$ & 496,18 & 516,78 & 553,01 & 444,82 & 467,31 & 9,93 \\
\hline
\end{tabular}

${ }^{\mathrm{E}}$ Efeito quadrático $(\mathrm{P}<0,05)$. $\mathrm{CV}=$ coeficiente de variação.

No entanto, o consumo de ração (CR) e a conversão alimentar (CA) foram influenciados pelos níveis de inclusão da raspa integral de mandioca (RIM), segundo as equações: $\mathrm{CR}=3,769-$ 0,0587 RIM + 0,004 RIM $^{2}\left(\mathrm{R}^{2}=\right.$ 0,7931; $\mathrm{P}<0,05$; Ponto Mínimo $=$ $7,34 \%)$ e $\mathrm{CA}=1,9696-0,0423 \mathrm{RIM}+$ $0,0024 \mathrm{RIM}^{2} \quad\left(\mathrm{R}^{2}=0,9793 ; \mathrm{P}<0,05\right.$, Ponto Mínimo $=8,81 \%$. O índice de eficiência produtiva também apresentou efeito quadrático, segundo a equação: $\mathrm{IEP}=501,47+5,4426 \mathrm{RIM}-0,4018$ $\mathrm{RIM}^{2}\left(\mathrm{R}^{2}=0,43, \mathrm{P}=6,80\right.$, Ponto máximo $=6,77 \%$ ).

Ao se fundamentar nas médias das variáveis que têm representatividade econômica, como a conversão alimentar e o índice de eficiência produtiva, no período de um a 42 dias de frango de corte, os dados das equações mostram que os níveis recomendados para inclusão de raspa integral da raiz da mandioca apresentaram valores diferentes, que foi para a conversão alimentar o valor mínimo obtido com $8,81 \%$ de inclusão, e para o índice de eficiência produtiva o valor máximo indicado foi de $6,77 \%$. Como o índice de eficiência produtiva é uma variável que em sua composição envolve o ganho de peso, a viabilidade da criação, a conversão alimentar e o número de dias da fase estudada, assim, optou-se por esta variável para definição do nível de inclusão da raspa integral da raiz da mandioca na alimentação dessas aves, cujo valor foi de $6,77 \%$. Esse valor mostrou-se inferior 
aos 10,24\% de inclusão da raspa da mandioca recomendado por Nascimento et al. (2005), ao encontrarem efeito quadrático para ganho de peso e conversão alimentar, quando substituíram o milho pela raspa da raiz da mandioca nos níveis $(0 ; 5 ; 10 ; 15 ; 20$ e $25 \%)$. $\mathrm{Na}$ fase de engorda, em função dos resultados negativos, com ocorrência de diminuição de ganho de peso e piora na conversão alimentar dos animais, os autores não recomendam a utilização desse produto.

No período estudado, também foi constatado que as aves apresentaram ganho de peso nos diversos tratamentos, inferior ao padrão da linhagem. Esta ocorrência pode estar vinculada, em parte, ao fato do experimento ter sido desenvolvido em ambiente de altas temperaturas, consequentemente em zona de desconforto térmico. A esse respeito, Lana et al. (2000) relataram que a temperatura ambiente é considerada $\mathrm{o}$ fator físico de maior efeito no desempenho de frangos de corte, visto que exerce grande influência no consumo de ração, pois se tem como consequência efeito direto no ganho de peso e na conversão alimentar desses animais. Devido o frango de corte ser muito sensível à temperatura ambiente elevada, seu desempenho fica prejudicado, o que resulta em atraso no crescimento e consequentemente, baixo peso à idade de abate, além de provocar aumento na temperatura retal e na frequência respiratória (SILVA et al., 2003) e estresse pelo calor (DIONELLO et al., 2002). $\mathrm{O}$ conforto térmico no interior de instalações avícolas é dessa forma importante, pois condições climáticas inadequadas afetam negativamente $\mathrm{o}$ desempenho do animal. Assim, nos climas tropical e subtropical, é indispensável o estudo das características ambientais de cada região (FURLAN et al., 2001; PELICANO et al., 2005). Ainda, a respeito do baixo desempenho das aves, merece destaque as afirmações de Longo et al. (2005), ao relatarem que na farinha da raiz de mandioca, que tem constituição semelhante à raspa integral da raiz da mandioca, usada neste experimento, existem grânulos de amido e polissacarídeos não amiláceos (PNA) que podem não ser bem digeridos pelas aves e causar flatulência e transtornos digestivos, o que provoca má absorção dos glicosídeos derivados da sacarose e do amido e, consequentemente, queda no desempenho das aves.

Ao se considerar que no presente estudo foi adicionado em todos os tratamentos experimentais um complexo enzimático, constituído de amilase, protease, celulase e fitase, dessa forma e em parte, o complexo enzimático utilizado pode ter contribuído para o nível de recomendação $6,77 \%$ de inclusão de raspa integral de raiz mandioca em ração de frangas de corte em ambientes de elevadas temperaturas.

Os resultados obtidos para o peso da carcaça, dos principais cortes e dos órgãos comestíveis não foram influenciados $(\mathrm{P}>0,05)$ pelos níveis de inclusão da raspa integral da raiz de mandioca para frangos de corte, no período de um a 42 dias (Tabela 6).

O mesmo comportamento foi observado com relação aos valores percentuais da carcaça (Tabela 7), dos principais cortes e dos órgãos comestíveis $(\mathrm{P}>0,05)$.

Estes resultados mostram que a raspa integral da raiz de mandioca usada nas rações de frango de corte no período de um a 42 dias, não afeta as características de carcaça, o peso dos principais cortes e órgãos quando a dieta é devidamente balanceada. No entanto, o peso final das aves, em todos os tratamentos não correspondeu ao valor esperado para a linhagem Ross, utilizada neste 
Rev. Bras. Saúde Prod. Anim., Salvador, v.13, n.1, p.160-172 jan/mar, 2012 http://www.rbspa.ufba.br ISSN 15199940

experimento. Santos et al. (2005) não obtiveram diferenças significativas para características de carcaça para aves de pescoço pelado, assim como Wang et al. (2009). Provavelmente, as altas temperaturas registradas durante a fase experimental podem ter contribuído para a redução do peso, o que se encontra em consonância com Oliveira Neto, et al. (2006), ao concluírem que em frangos de corte de um a 49 dias de idade submetidos a ambiente de altas temperaturas $\left(32^{\circ} \mathrm{C}\right)$ têm o desempenho e o rendimento de cortes nobres comprometidos.

Tabela 6. Valores absolutos do peso da carcaça, cortes e órgãos comestíveis de frangos de corte (g), abatidos aos 42 dias de idade, alimentados com rações contendo diferentes níveis de inclusão de raspa integral da raiz de mandioca

\begin{tabular}{|c|c|c|c|c|c|c|}
\hline \multirow{2}{*}{ Variáveis } & \multicolumn{5}{|c|}{ Níveis de inclusão da raspa integral da mandioca $(\%)^{1}$} & \multirow{2}{*}{ CV $(\%)$} \\
\hline & 0 & 5 & 10 & 15 & 20 & \\
\hline Peso vivo & 1910,50 & 1851,50 & 2046,50 & 1885,25 & 1921,50 & 4,5 \\
\hline Peso carcaça & 1411,25 & 1341,00 & 1495,50 & 1370,00 & 1392,50 & 4,8 \\
\hline Peito & 452,75 & 431,75 & 486,00 & 432,25 & 460,00 & 6,6 \\
\hline Dorso & 390,38 & 367,13 & 389,13 & 368,50 & 362,63 & 8,0 \\
\hline Coxas & 203,125 & 194,375 & 211,250 & 210,375 & 197,875 & 5,8 \\
\hline Sobrecoxas & 206,63 & 195,88 & 233,50 & 97,75 & 209,38 & 8,0 \\
\hline Asas & 76,500 & 69,625 & 79,875 & 78,000 & 75,875 & 5,7 \\
\hline Entreasas & 82,00 & 82,25 & 87,00 & 83,38 & 87,50 & 19,4 \\
\hline Coração & 8,125 & 8,750 & 8,875 & 8,250 & 9,125 & 13,2 \\
\hline Fígado & 37,625 & 36,000 & 36,625 & 37,000 & 37,000 & 7,6 \\
\hline Moela & 53,875 & 58,000 & 64,000 & 65,750 & 61,000 & 12,6 \\
\hline
\end{tabular}

${ }^{1}$ Não houve efeito significativo $(\mathrm{P}>0,05)$. $\mathrm{CV}=$ coeficiente de variação.

Tabela 7. Valores percentuais da carcaça, cortes e órgãos comestíveis de frangos de corte (\%), abatidos aos 42 dias de idade, alimentados com rações contendo diferentes níveis de inclusão de raspa integral da raiz de mandioca

\begin{tabular}{|c|c|c|c|c|c|c|}
\hline \multirow{2}{*}{ Variáveis $(\%)$} & \multicolumn{5}{|c|}{ Níveis de inclusão da raspa integral da mandioca (\%) } & \multirow{2}{*}{$\mathrm{CV}(\%)$} \\
\hline & 0 & 5 & 10 & 15 & 20 & \\
\hline Peso vivo & 100,00 & 100,00 & 100,00 & 100,00 & 100,00 & - \\
\hline Peso carcaça ${ }^{1}$ & 73,87 & 72,42 & 73,09 & 72,69 & 72,45 & 1,41 \\
\hline Peito $^{1}$ & 32,07 & 32,20 & 32,47 & 31,56 & 32,96 & 4,61 \\
\hline Dorso $^{1}$ & 27,60 & 27,41 & 26,01 & 26,89 & 26,07 & 4,93 \\
\hline Coxas $^{1}$ & 14,39 & 14,49 & 14,13 & 15,34 & 14,24 & 4,48 \\
\hline Sobrecoxas ${ }^{1}$ & 14,73 & 14,57 & 15,63 & 14,43 & 15,05 & 8,65 \\
\hline Asas $^{1}$ & 5,41 & 5,19 & 5,34 & 5,69 & 5,44 & 4,80 \\
\hline Entreasas $^{1}$ & 5,79 & 6,11 & 5,80 & 6,69 & 6,34 & 18,57 \\
\hline Coraçãa $^{1}$ & 0,57 & 0,65 & 0,59 & 0,60 & 0,65 & 12,45 \\
\hline Fígado 1 & 2,67 & 2,68 & 2,45 & 2,69 & 2,66 & 9,44 \\
\hline Moela $^{1}$ & 3,81 & 4,32 & 4,28 & 4,80 & 4,37 & 13,28 \\
\hline
\end{tabular}

${ }^{\mathrm{T}}$ Não houve efeito significativo $(\mathrm{P}>0,05)$. $\mathrm{CV}=$ coeficiente de variação. 
Amaral et al. (2011), Geraert et al. (1996) e Oliveira Neto et al. (2000) também constataram que independente do nível energético da ração a alta temperatura ambiente influencia negativamente $\mathrm{o}$ desempenho, o rendimento de peito e o peso dos órgãos vitais, bem como determina aumento da deposição de gordura abdominal de frangos de corte.

A raspa integral da raiz de mandioca pode ser utilizada em dietas balanceadas de frangos de corte, no período de um a 42 dias, até o nível de $6,77 \%$, sem comprometer as características da carcaça e o rendimento dos principais cortes e dos órgãos comestíveis.

\section{AGRADECIMENTOS}

Os autores agradecem à coordenação de Aperfeiçoamento de Pessoal de Nivel SuperiorCAPES/PROCAD e ao Centro de Ciencias Agrárias, Departamento de Zootecnia da Universidade Federal do Piauí pelo apoio financeiro na realização deste estudo.

\section{REFERÊNCIAS}

ALMEIDA, J.; FERREIRA FILHO, J.R. Mandioca: uma boa alternativa para Alimentação Animal. Bahia Agrícola, v.7, n.1, p.50-56, 2005.

AMARAL, A.G., YANAGI JUNIOR, T.; LIMA, R.R; TEIXEIRA, V.H; SCHIASSI, L. Efeito do ambiente de produção sobre frangos de corte sexados criados em galpão comercial.

Arquivo Brasileiro de Medicina Veterinária e Zootecnia, v.63, n.3, p.649-658, 2011.
CARRIJO, A.S.; FASCINA, V.B.; SOUZA, K.M.R. ; RIBEIRO, S.S.; ALLAMAN, I.B.; GARCIA, A.M.L.; HIGA, J.A. Níveis de farelo da raiz integral de mandioca em dietas para fêmeas de frangos caipiras. Revista Brasileira de Saúde e Produção Animal[Online], v.11, n.1, p.131-139, 2010.

COBB. Manual de manejo de frangos de corte Cobb. 2009. 65 p. Disponível em: $<$

http://www.granjaplanalto.com.br/Manu al\%20Frango\%20Corte_20_03_09.pdf $>$ . Acesso em: 10 jan. 2011.

DIONELLO, N.J.L.; MACARI, M.; FERRO, J.A.; RUTZ, F.; FERRO, M.I.T.; FURLAN, L.R. Respostas fisiológicas associadas à termortolerância em pintos de corte de duas linhagens por exposição a altas temperaturas. Revista Brasileira de Zootecnia, v.31, n.1, p.79-85, 2002.

FASUYI, O.A.; ALETOR, V.A. Varietal Composition and functional properties of cassava (Manihote sculenta, Crantz) leaf mealand leaf protein concentrates. Paskistan Journal of Nutrition, v.1, n. 1, p.43-49, 2005.

FERREIRA, G.D.G.; OLIVEIRA, R.L.; CARDOSO, E.C.; MAGALHÃES, A.L.R.; BRITO, E.L. Valor nutritivo de co-produtos da mandioca. Revista Brasileira de Saúde e Produção Animal [Online], v.8, n.4, p.364-374, 2007.

FERREIRA, R. A. Maior produção com melhor ambiente para aves, suínos e bovinos. Viçosa: Aprenda Fácil, 2005. 371p. 
Rev. Bras. Saúde Prod. Anim., Salvador, v.13, n.1, p.160-172 jan/mar, 2012 http://www.rbspa.ufba.br ISSN 15199940

FURLAN, R.L.; CARVALHO, N. C.; MALHEIROS, E. B.; MACARI, M.

Efeito da restrição alimentar inicial e da temperatura ambiente sobre o desenvolvimento de vísceras e ganho compensatório em frangos de corte.

Arquivo Brasileiro de Medicina

Veterinária e Zootecnia, v.53, n.4, p.1-7, 2001.

GERAERT, P.A.; PADILHA, J.C.F.; GUILLAUMIN, S. Metabolic and endocrine changes induced by chronic heat exposure chickens: biological and endocrinological variables. British Journal Nutrition, v.75, p.205-216, 1996.

LANA, G.R.Q.; ROSTAGNO, H.S.; ALBINO, L.F.T.; LANA, Â.M.Q.Efeito da Temperatura Ambiente e da Restrição Alimentar sobre o Desempenho e a Composição da Carcaça de Frangos de Corte. Revista Brasileira de Zootecnia, v.29, n.4, p.1117-1123, 2000.

LONGO, F.A.; MENTEN, J.F.M.; PEDROSO, A.A.; FIGUEIREDO, A.N.; RACANICCI, A.M.C., GAIOTTO, J.B., SORBARA, J.O.B. Carboidratos na dieta pré-inicial de frangos de corte. Revista Brasileira de Zootecnia, v.34, n.1, p.123133, 2005.

NASCIMENTO, G.A.J.; COSTA, F.G.P.; AMARANTE JÚNIOR, V.S.; BARROS, L.R. Efeitos da substituição do milho pela raspa de mandioca na alimentação de frangos de corte, durante as fases de engorda e final.Ciência e Agrotecnologia, v.29, n.1, p.200-207, 2005.

OLIVEIRA NETO, A.R.; ABREU, M.L.T.; DONZELE, J.L.; FERREIRA, L.A. Efeitos da temperatura e da umidade relativa sobre o desempenho e o rendimento de cortes nobres de frangos de corte de 1 a 49 dias de idade. Revista

Brasileira de Zootecnia, v.35, n.3, p.797803, 2006.
OLIVEIRA NETO, A.R.; OLIVEIRA, R.F.; DONZELE, J.L.; FERREIRA, L.A.; EUCLYDES, R.F.; CARDOSO, L.L. Efeito da temperatura ambiente sobre o desempenho e características de carcaça de frangos de corte alimentados com dieta controlada e dois níveis de energia metabolizável. Revista

Brasileira de Zootecnia, v.29, n.1, p.183-190, 2000.

PELICANO, E.R.L.; BERNAL, F.E.M.; FURLAN, R.L.; MALHEIROS, E.B.; MACARI, M. Efeito da temperatura ambiente e da restrição alimentar protéica ou energética sobre ganho de peso e crescimento ósseo de frangos de corte. Arquivo Brasileiro de Medicina Veterinário e Zootecnia, v.57, n.3, p.353-360, 2005.

ROSTAGNO, H.S. ALBINO, L.F.T. DONZELE, J.L.; GOMES, P.C.; OLIVEIRA, R.F. Tabelas brasileiras para aves e suínos: composição de alimentos e exigências nutricionais. 2.ed. Viçosa: Universidade Federal de Viçosa, 2005. 186p.

SANTOS, A.L.; SAKOMURA, N.K.; FREITAS, E.R.; FORTES, C.M.S; CARRILHO, E.N.V.M. Comparison of free range broiler chicken strains raised in confined or semi-confined systems. Brazilian Journal of Poultry Science, v.7, n.2, p.85-92,2005.

SILVA, M.A.N.; HELLMEISTER FILHO, P.; ROSÁRIO, M.F.; MARTINS, E.; COELHO, A.A.D.; SAVINO, V.J.M.; SILVA, I.J.O. Influência do sistema de criação sobre o desempenho, condição físiológica e o comportamento de linhagens de frango de corte. Revista Brasileira de Zootecnia, v.32, n.1, p.208-213, 2003. 
Rev. Bras. Saúde Prod. Anim., Salvador, v.13, n.1, p.160-172 jan/mar, 2012 http://www.rbspa.ufba.br ISSN 15199940

STRINGHINI, J.H.; ANDRADE, M. L.; ANDRADE, L.; ROCHA, P.T.; ROSA, R.M. Desempenho, balanço e retenção de nutrientes e biometria dos órgãos digestivos de frangos de corte alimentados com diferentes níveis de proteína na ração pré-inicial. Revista Brasileira de Zootecnia, v.35, n.6, p.2350-2358, 2006.

SAS INSTITUTE. Statistical analysis system: system for linear models.

Cary, 1986. 211p.
WANG, K.H.; SHI, S.R.; DOU, T.C.;

SUN, H.J. Effect of a free-range raising system on growth performance, carcass yield, and meat quality of slow-growing chicken. Poultry Science, v.88, n.10, p.2219-2223, 2009.

Data de recebimento: 27/05/2011

Data de aprovação: 09/12/2011 